\title{
COMPRAS E CONTRATAÇÕES PÚBLICAS FEDERAIS SUSTENTÁVEIS: DESAFIOS NA PARTICIPAÇÃO DE MICRO E PEQUENAS EMPRESAS DO MUNICÍPIO DE SÃO MATEUS/ES
}

\author{
Helaine do Amaral MOTTA ${ }^{1}$ \\ Lilian Firme Pittou de OLIVEIRA ${ }^{2}$ \\ ${ }^{1}$ Faculdade Vale do Cricaré - FVC. Mestre em Gestão Social, Educação e Desenvolvimento Regional,Faculdade \\ Vale do Cricaré - São Mateus (ES), Brasil. helainemotta@ hotmail.com \\ ${ }^{2}$ Faculdade Vale do Cricaré - FVC. Doutora em Agronomia, Universidade Federal de São Paulo - USP, (SP), \\ Brasil. helainemotta@hotmail.com
}

Recebido em: 07/04/2015 - Aprovado em: 19/08/2015 - Disponibilizado em: 30/10/2015

\section{Resumo}

Este trabalho tem como objetivo identificar os desafios das Microempresas e Empresas de Pequeno Porte (MPEs) que participaram das Compras Públicas Federais Sustentáveis e seu papel no desenvolvimento sustentável. Foi desenvolvida uma pesquisa exploratória, qualitativa e quantitativa, bibliográfica com estudo de caso. O principal instrumento metodológico, portanto, compôs-se de questionários aplicados junto às MPEs do município de São Mateus-ES. O estudo frisa, ainda, a importância das MPEs no desenvolvimento local e, em consequência, no desenvolvimento do país e analisa os pontos em que o Governo Federal, no uso das políticas públicas como ferramentas para o aumento da competitividade das MPEs, ajuda a promover a sobrevivência destas empresas nos grandes mercados. Os resultados da pesquisa demonstraram que o maior desafio das MPEs é a falta de informação sobre o processo licitatório, que vai desde a divulgação até ao levantamento da documentação necessária. $\mathrm{O}$ estudo revelou, também, que há a necessidade de se capacitar as empresas locais para que participem e obtenham resultados positivos nas licitações de Compras Públicas Sustentáveis.

Palavras-chave: Microempresas e Empresas de Pequeno Porte, Compras públicas e Compras públicas Sustentáveis.

\begin{abstract}
This work aims to identify the challenges of Small and Micro Enterprises (SMEs) which participate in the Federal Sustainable Public Procurement and its role in sustainable development. An exploratory, qualitative and quantitative research with case study was developed. The main methodological tool, therefore, consisted of questionnaires applied to SMEs in São Mateus-ES. The study would also point out the importance of SMEs in local development and, consequently, in the development of the country and analyzes the points where the Federal Government uses public policies as tools to increase the competitiveness of SMEs and help these companies stay in large markets. The survey results showed that the greatest challenge of the MSC is the lack of information on the bidding process, ranging from disclosure until the lifting of the necessary documentation. The study also revealed that it is necessary for local businesses participating and achieving positive results in the Sustainable Public Procurement bidding.
\end{abstract}

Keywords: Small and Micro Enterprises, Public Procurement and Sustainable Public Procurement. 


\section{Introdução}

As Micro e Pequenas Empresas (MPE) respondem por uma parte considerável da geração de empregos e do Produto Interno Bruto (PIB) brasileiro. As MPE constituem-se em $99 \%$ de todas as empresas nacionais e contribuem com $70 \%$ dos empregos gerados e 25\% do PIB brasileiro (BARRETO, 2013).

A despeito do ambiente complexo e burocrático do mercado brasileiro, com altas taxas de juros, ainda há a preocupação com as questões socioambientais. Quando usada positivamente, esta preocupação com o meio ambiente acaba por melhorar a imagem institucional que, por sua vez, faz aumentar as vendas, o número de consumidores, de emprego e qualidade de vida, tanto para o público interno quanto o externo (CLARO \& AMÂNCIO, 2008).

No Governo Federal, contexto analisado nesta pesquisa, um exemplo destes mercados preocupados com as questões socioambientais são as Compras Públicas Sustentáveis (CPS).

Estatísticas apontam que, em geral, as compras públicas do governo representam, anualmente, $20 \%$ do PIB brasileiro (BRASIL, 2013b). O contexto mundial não é diferente. Segundo o subsecretário-geral das Nações Unidas e diretor executivo do Programa das Nações Unidas para o Desenvolvimento, Achim
Steiner, está claro que os países integrantes da Organização para Cooperação Econômica e Desenvolvimento (OECD) gastam 13\% do seu PIB, em média por ano, em compras públicas. Em alguns países em desenvolvimento, como o Brasil, este índice chega a 20\%. Ou seja, Steiner vê a oportunidade de que este montante de recursos financeiros possa beneficiar e impulsionar os mercados em direção à sustentabilidade (ALMEIDA, 2014). Isso significa trilhões de dólares direcionados para este "novo" mercado.

De acordo com estimativas recentes (VIEIRA, 2013), as microempresas capixabas representam $99 \%$ das empresas do estado e tem a sexta melhor taxa de sobrevivência no mercado nacional. Ao todo são 123 mil estabelecimentos, os quais concentram mais de $58,5 \%$ de todos os postos de trabalho. Em contrapartida, algumas estatísticas apontam que $35 \%$ delas encerram as atividades no primeiro ano após a abertura e somente $20 \%$ conseguem sobreviver por mais de cinco anos (SEBRAE, 2007; FERNANDES, 2013). A ingerência das MPEs e o desconhecimento do mercado são apontados como as causas principais do encerramento de atividades.

Sendo assim e levando-se em conta o potencial crescente dos mercados sustentáveis, buscou-se elucidar parte dos desafios das MPEs da cidade de São Mateus com relação à 
participação nas licitações públicas federais com critérios de sustentabilidade. Assim, acredita-se delimitar quais as tendências para o ambiente nacional e/ou quais questões são válidas para estudos futuros. Pode-se perceber que existem pouquíssimas ou nenhuma pesquisa nos acervos acadêmicos sobre o desempenho das MPEs nas Contratações Públicas (com e sem critérios de sustentabilidade), principalmente no Estado do Espírito Santo (SAMPAIO, 2012).

São Mateus é o oitavo município mais antigo do Espírito Santo, tem população de cerca de 110 mil habitantes e área de $2.338 \mathrm{~km}^{2}$ (IBGE, 2014). O número de empresas no município é de 9.958, das quais, 6.216 são MPEs, ou seja, 63\% do total (INCAPER, 2011). A maior parte destas empresas pertence ao setor de serviços e comércio e são responsáveis por $65 \%$ do PIB municipal (idem, ibidem), juntamente com o setor de royalties dos plantios de eucalipto e extração de petróleo.

Em um primeiro momento, levantaramse os dados oficiais dos anos de 2012 e 2013 referentes à atuação das MPEs junto às entidades federais. Daí, seguiram-se análises da trajetória de certas empresas no processo de contratação com o Governo Federal. Os nomes destas empresas foram mantidos em sigilo, bem como o de todos os participantes entrevistados. Há que se pensar que o potencial deste mercado é grande e promissor e esta é a justificativa para o estudo das dificuldades que as MPEs encontram em sua participação nas licitações.

\section{Microempreas e Pequenas Empresas} (Mpes), Licitações E Sustentabilidade

Com a criação do CEBRAE - Centro Brasileiro de Assistência Gerencial à Pequena Empresa, em 1972, e sua conversão mais tarde em Serviço Brasileiro de Apoio às Micro e Pequenas Empresas (SEBRAE), em 1990, as MPEs passaram a ganhar maior vulto no cenário nacional. No entanto, o grande marco do desenvolvimento das MPEs se deu em 2006, com a então promulgação da Lei Geral das Micro e Pequenas Empresas, publicada como Lei Complementar $n^{\circ}$. 123/06 (BRASIL, 2006). Os principais benefícios e incentivos do Governo para o setor estão nesta lei, a qual estabelece tratamento diferenciado às MPEs por parte das instituições públicas e paraestatais.

De acordo com a LC 123/06, microempresas ou empresas de pequeno porte são toda sociedade empresária simples individual de responsabilidade limitada do empresário, que esteja devidamente inscrita no Registro de Empresas Mercantis ou no Registro Civil de Pessoas Jurídicas, e que tenham receita bruta anual igual ou inferior a $\mathrm{R} \$ 360$ mil, de acordo com o art. 966 da Lei número 10.406 de 2002. Da mesma forma, as empresas de pequeno porte (EPP) são enquadradas entre 
as que auferem receita bruta superior a $R \$ 360$ mil e igual ou inferior a $\mathrm{R} \$ 3,6$ milhões (BRASIL, 2002).

Segundo Cerino (2009), a importância dessa legislação para o futuro destes pequenos negócios está nos incentivos que ela implanta, como o regime unificado de apuração e recolhimento dos impostos em todas as esferas; a desoneração tributária das receitas de exportação e substituição tributária; a dispensa do cumprimento de certas obrigações trabalhistas e previdenciárias; a simplificação do processo de abertura, alteração e encerramento das atividades; a facilitação do acesso ao crédito e ao mercado; preferência nas compras públicas; o estímulo à inovação tecnológica; o incentivo ao associativismo na formação de consórcios para fomentação de negócios; o incentivo à formação; a regulamentação da figura do pequeno empresário e o parcelamento de dívidas tributárias para adesão ao Simples Nacional.

Inseridas neste nicho, estão as empresas sustentáveis. Aquelas que adotam políticas e práticas que atendam aos critérios de eficiência econômica, preservação do meio ambiente e responsabilidade social (ZAMBON \& RICCO, 2011). Estas empresas carregam consigo as preocupações com a sustentabilidade frente às novas exigências legais, sociais, mercadológicas e governamentais (CAREON E SILVA, 2010).
De acordo com a Lei de Licitações (Lei número 8.666/1993), todas estas empresas, ao contratar com Administração Pública, devem observar rígidos dispositivos. Afinal, 20\% do PIB brasileiro é movimentado pelas compras públicas.

Segundo Mello (2012, p. 483),

Já para Justen Filho (2010, p.251),

A licitação é um
procedimento administrativo
que envolve a realização de
diversas atividades materiais,
a cargo de uma pluralidade
de agentes públicos e
envolvendo um número
variável de particulares. Essa
sucessão de atos poderá
materializar-se em diferentes
locais geográficos, a
depender do objeto da
atuação pública ou privada.

De acordo com Castro (2010, p. 7), o conceito de licitação, sob o ponto de vista do fornecedor, "é um processo utilizado pelas 
entidades públicas, que usam o dinheiro público arrecadado na forma de impostos e taxas para contratar obras e serviços e comprar e vender bens patrimoniais".

Mukai (1990, p. 54) ensina que: "Os procedimentos de licitação compõem-se de uma fase interna que se estende até a elaboração do edital ou carta-convite; e de uma fase externa, que se inicia com a publicação do edital ou expedição da carta-convite e termina com a adjudicação do objeto da licitação." São exemplos de requisitos a serem atendidos durante a fase interna: Objeto $^{1}$ da Licitação, a Escolha da Modalidade e do tipo de licitação; confecção do Edital de Licitação ou CartaConvite (FARIA JUNIOR e BERNADES, 2010).

A definição de sustentabilidade das licitações se consolidou junto com o conceito de "Desenvolvimento Sustentável", em 1987, quando a Organização das Nações Unidas (ONU) publicou o relatório de Brundtland, ou "Nosso Futuro Comum", definindo desenvolvimento sustentável como aquele que satisfaz às necessidades das gerações atuais sem comprometer a capacidade das gerações futuras de satisfazer as suas próprias necessidades (BRUNDTLAND, 1987).

${ }^{1}$ Entende-se por objeto da licitação a obra, serviço, compra, alienação e locação ou concessão, as quais serão, por fim, contratadas com o particular vencedor da licitação (BRASIL, 1993).
Esse conceito evidenciou a importância da interdependência entre a área econômica, a social e a ambiental. A dimensão social representa a construção de uma sociedade mais justa, que incentive o desenvolvimento humano e a qualidade de vida, ou seja, melhor distribuição de renda e bens, incluindo a redução da pobreza. Já a dimensão econômica requer alocação mais eficiente dos recursos públicos e privados, sem perder rentabilidade frente à sustentabilidade. A dimensão ambiental está ligada às condições de vida das futuras gerações, e diz respeito a um meio ambiente hígido, sem degradação (FREITAS, 2012).

Nas atuais práticas, o ordenamento jurídico incluiu o desenvolvimento sustentável como finalidade da licitação e o colocou ao lado de dois pilares: isonomia e seleção da proposta mais vantajosa para o interesse público.

Desde então, com o advento da lei 12.349, que acrescentou a sustentabilidade aos princípios da isonomia, as compras públicas passaram a ser um meio de induzir as empresas a fornecer à administração pública a adequação de seus produtos e processos administrativos e operacionais em prol da sustentabilidade do meio ambiente.

Desta forma, o panorama de busca do desenvolvimento sustentável implica ações efetivas na sociedade, nas empresas e, principalmente, no governo, que, além de 
normatizar e fiscalizar as ações vindas da sociedade e das empresas, deve, também, manter postura ativa ao fiscalizar e melhorar a si próprio, sendo tão promotor da sustentabilidade quanto a iniciativa privada (BURG et al., 2014).

Seguindo esta mesma visão, Machado (2002, p. 67), assegura que:

É fundamental ter presente que os governos são importantes atores econômicos e, portanto, o uso adequado dos investimentos públicos pode significar, direta ou indiretamente, maior ganho social e ambiental, quer seja devido à possibilidade de geração de novos empregos, ao uso racional dos recursos naturais ou à melhoria da qualidade de vida da população.

\subsection{Compras Públicas Sustentáveis}

A partir destes princípios, as compras públicas sustentáveis - também conhecidas como licitações sustentáveis ou ecoaquisição (BIDERMAN et al., 2008), são definidas da seguinte forma:

As compras públicas sustentáveis (CPS) são uma solução para integrar as considerações ambientais e sociais em todas as fases do processo de compra e contratação dos governos, com o objetivo de reduzir os impactos à saúde humana, ao meio ambiente e aos direitos humanos, ao mesmo tempo resultando em economia para a administração pública. (ICLEI, 2013, p. 14)

Compras Públicas Sustentáveis representam o processo pelo qual as organizações buscam atender as suas necessidades de bens, serviços, obras e serviços públicos de uma forma tal que os benefícios ambientais e sociais alcançados sejam maiores do que o custo de aquisição a longo prazo. Em suma, o processo é voltado não só para a organização, como também para a sociedade e a economia, ao mesmo tempo em que busca amenizar os danos ao meio ambiente.

Seguindo esta mesma linha de pensamento, as Nações Unidas (United Nations, 2008) complementam que:

Aquisição ambientalmente responsável ou 'verde' é a seleção de produtos e serviços que minimizam os impactos ambientais. Ela exige uma empresa ou organização para realizar uma avaliação dos impactos ambientais de um produto em todas as fases do seu ciclo de vida. Isso significa considerar os custos ambientais de garantir matérias-primas e fabricação, transporte, armazenamento, manipulação, utilização e eliminação do produto. Além das preocupações ambientais compras sustentáveis, também incorpora considerações sociais (Nações Unidas, 2008, tradução livre). 
Um dos fatores de maior relevância nas compras públicas é o ciclo de vida do produto, uma vez que o comprador tem como premissa principal os custos ambientais e sociais, ao invés do preço de aquisição (SAEB e ICLEI, 2012). Os critérios e práticas de sustentabilidade são executados de acordo com a especificação técnica do objeto e o contido no artigo $3^{\circ}$ da Lei $8.666 / 93$, o qual descreve os princípios que regem a execução dos serviços contratados e o fornecimento de bens.

O Ministério do Planejamento (BRASIL, 2014c), através do relatório da Secretaria de Logística e Tecnologia da Informação (SLTI), aponta que, entre janeiro e dezembro de 2013, as aquisições governamentais movimentaram $\mathrm{R} \$ 68,4$ bilhões na aquisição de bens e serviços. Desse total, as MPE participaram com 30\%, o que corresponde a R\$ 20,5 bilhões. Este resultado apontou um crescimento de $33 \%$ da participação das MPE nas compras governamentais de 2013 em relação a 2012 (BRASIL, 2014a). Ao todo, as Contratações Públicas Sustentáveis no Brasil movimentaram $\mathrm{R} \$ 40,4$ milhões, o que representa $0,06 \%$ do total das compras públicas. Em comparação com o mesmo período de 2012, as aquisições sustentáveis sofreram um aumento de $1 \%$.

Embora a evolução da CPS entre os anos de 2012 e 2013 seja pouco expressiva, no primeiro trimestre de 2014 o crescimento desse mercado ficou em torno de $66 \%$ maior do que o mesmo período do ano anterior. Porém, entre 2010 e 2012, houve um crescimento significativo de $237 \%$. Um dos justificadores para este aumento vertiginoso vem da imposição das novas leis com relação à sustentabilidade nas aquisições públicas e a corrida em manter as condições climáticas para o pleno desenvolvimento da vida. Estes fatos ratificam que o mercado da sustentabilidade tende a um potencial de expansão ainda pouco percebido (BRASIL, 2014b).

\section{Materiais e Métodos}

Esta pesquisa é de cunho qualitativo e quantitativo (SAMPIERI, 2006). Entretanto, para que fosse possível uma investigação coesa e completa, a pesquisa foi exploratória e descritiva. Exploratória, porque não se encontraram informações científicas que atendessem às necessidades objetivas deste trabalho. Descritiva, porque tem como objetivo conhecer e descrever os atores de um mercado específico - o das contratações públicas regionais, bem como entender o seu comportamento para a formulação de estratégias (VERGARA, 2011).

Definiu-se como população de pesquisa as Microempresas e empresas de pequeno porte do município de São Mateus. De acordo com dados do cadastro do setor de tributação, 
existem 9.958 empresas de todos os portes no município, o que torna São Mateus o pólo regional de atração de investimento e crescimento populacional do Norte do Espírito Santo. Neste universo de empresas, selecionouse aquelas que fazem parte do comércio atacadista e varejista e que comercializam, entre outros produtos, o papel A4 reciclado e aparelho de ar condicionado com padrões de sustentabilidade.

Desta forma, a amostra analisada foi composta por 89 microempresas e empresas de pequento porte. O foco nos itens "papel A4 reciclado" e "Aparelho de ar condicionado" se justifica por estes produtos estarem no topo da lista dos produtos sustentáveis mais adquiridos pelos órgãos públicos federais localizados na região de São Mateus e que tenham licitado entre 2012 e 2013 (BRASIL, 2014d).

Portanto, para os efeitos desta pesquisa foram considerados os órgãos: Instituto da Seguridade Social (INSS), Departamento da Polícia Federal (DPF), Receita Federal do Brasil (RFB), Polícia Rodoviária Federal (PRF), Ministério Público (MP), Instituto Federal de Educação, Ciência e Tecnologia do Espírito Santo (Ifes) e o Centro Universitário Norte do Espírito Santo (CEUNES).

Os questionários foram aplicados na versão online com perguntas fechadas e abertas com base em um roteiro definido em forma de categorias (BABBIE, 1999 e FREITAS et al.,
2000), que pôde ser acessado num sítio eletrônico, por meio de um link disponibilizado aos participantes através de correio eletrônico ou entrega in loco, ou em forma de questionário impresso, como forma de estimular a participação e aumentar o nível de retorno.

Foram investigadas as características pessoais das empresas que compõem esta amostragem, como, por exemplo, o tempo de vida no mercado, a percepção das ações do governo federal a respeito do apoio às MPEs nas compras públicas, participação ou não em licitações junto ao governo federal e experiências e desafios frente a estas licitações. Por último, verificou-se qual o nível de adaptação destas empresas ao mercado de produtos sustentáveis.

\section{Resultados}

O papel A4 reciclado foi adquirido pelo Ifes em 2012 e em 2013 via Sistema de Registro de Preços (SRP), que é um processo em que o valor é inscrito em uma Ata de registro de preço e fica vigente por doze meses, podendo ser adquirido conforme a necessidade da instituição. Já o aparelho de ar condicionado foi adquirido na situação de compra direta, sem tempo de validade, através de três licitações. Este tipo de contratação ocorre de forma simples, pois é concluída após a cotação de preço. Uma das propostas será vencedora pelo 
quesito de menor preço e situação regular perante o fisco federal.

Nota-se que 51 empresas estavam aptas e cadastradas para participarem da licitação de Papel A4 e Aparelhos de Ar Condicionado. Dentre estas, 25 participaram das licitações para papel A4 reciclado e 26 para as de aparelho de ar condicionado.

Pelos critérios da Lei Complementar 123/06, $82 \%$ das empresas foram enquadradas como Microempresa (com faturamento anual de até R \$ 360 mil), 10\% como Pequena Empresa e 8\% como Microempreendedor. Destas, $41 \%$ têm tempo de existência de um a até cinco anos, $16 \%$ de cinco a dez anos, que é o período de maior mortalidade das MPEs (SEBRAE, 2007), e $43 \%$ com mais de dez anos no mercado.

Dos representantes das MPEs que responderam aos questionários, 3\% eram administradores; 43\%, proprietários; 38\%, funcionários e $16 \%$ matinham ligação indireta com os proprietários (como filhos, conjugue ou outros parentes).

Quando questionados sobre o conhecimento dos benefícios implementados pelo Governo Federal através da LC 123/06, $65 \%$ dos entrevistados afirmaram desconhecer qualquer subsídio ou benefício exclusivo para as MPEs. Acerca da percepção de oportunidades facilitadas por instrumentos oficiais, $57 \%$ foram taxativos quando afirmaram que falta qualquer oportunidade para este nicho do mercado. Ademais, $70 \%$ do total afirmaram ter dificuldade em negociar com a esfera federal do governo ou que os valores devidos não são repassados em observância com prazos praticáveis (43\%). Subtende-se que a maioria dos responsáveis e donos de micro e pequenas empresas desconhecem as formas e os benefícios de se fazer negócios com o governo federal.

Dentre as empresas que afirmaram conhecer os benefícios exclusivos das MPEs implementados pela lei $(35 \%$ do total de entrevistados), 27\% afirmaram conhecer que compras de valores inferiores a $\mathrm{R} \$ 80$ mil são de exclusividade das MPEs.

Observou-se, nas respostas às questões abertas, que as empresas citaram a palavra "burocracia" em cerca de 51\% das vezes (26 respostas), "oportunidade" em 24\% (12 respostas) e "divulgação" em 19\% das vezes. Estes dados refletem que as licitações ainda são burocráticas, as oportunidades não são suficientes e a divulgação dos certames é ineficiente.

Das empresas pesquisadas, apenas 3\% já participaram de alguma licitação (6 empresas, no total). Destas, $53 \%$ afirmaram ter grande dificuldade em cumprir com todos os requisitos dos editais de convocação, como também $83 \%$ não têm acesso às informações de ocorrência das licitações. O mesmo número se repete com relação ao levantamento da documentação de 
habilitação na licitação (emissão de certidões, certificados, etc).

Dentre os desafios elencados por estas empresas em sua relação com o governo, $91 \%$ reafirmaram ser complexa a forma de divulgação das licitações, o que impede que os certames tenham concorrências saudáveis. Outro desafio diz respeito à competitividade com empresas com mais tempo de mercado e financeiramente mais sólidas: $71 \%$ indicaram ser este o segundo principal desafio. Em seguida, tem-se que $60 \%$ e $51 \%$ não conseguem obter a documentação solicitada ou não conseguem contato com os servidores dos órgãos, respectivamente.

Apesar destes desafios, $83 \%$ das empresas que já participaram de licitações e $68 \%$ das que nunca participaram de licitações, afirmaram estar dispostas a contratar com o Governo Federal.

Com relação à sustentabilidade, constatou-se que $80 \%$ das empresas entrevistas demonstram estar preparadas ou se preparando para o mercado da sustentabilidade e que $61 \%$ têm facilidade de comercializar produtos sustentáveis, conforme resposta aos questionários. A maioria afirmou estar pronta para participar de licitações com critérios de sustentabilidade $(80 \%)$, pois possuem produtos com selos específicos, inclusive os averiguados nesta pesquisa. Um ponto que causa confusão em compras públicas sustentáveis é a diferenciação entre produtos sustentáveis e empresas sustentáveis, pois pode-se adquirir um produto com critério de sustentabilidade em uma empresa que apenas o comercializa, podendo não ter a sustentabilidade em seus processos administrativos, como é a realidade da maioria das empresas do segmento das MPE.

\section{Considerações Finais}

Portanto, este estudo evidenciou que as MPEs têm, como principais desafios, o levantamento da documentação necessária dentro do prazo exigido pelas licitações e a superação da concorrência desigual, evidenciada com a forma precária de divulgação das CPS. Sabe-se que um dos princípios norteadores da licitação é a publicidade (art. 3º, V, Lei 8.666/93). Há, portanto, um desequilíbrio entre o que é praticado pelos atos dos gestores das instituições federais e o que é exigido pela Lei, seja devido ao distanciamento das licitação da realidade dos empreendedores da região ou à veiculação em locais inapropriados ao público alvo.

Não é solução apenas a aprovação de mais leis de suporte às MPEs com relação às licitações de valor até $\mathrm{R} \$ 80.000$, mas é necessário investir em campanhas elucidatórias sobre os processos de licitação, para que, de fato, a relação de concorrência entre as 
pequenas e grandes empresas se tornem equilibradas quando da participação em compras públicas.

Existe a necessidade de capacitação dos empreendedores e empresários de micro e pequenas empresas do município, mesmo que através de palestras e cursos, para torná-los aptos a participarem das licitações federais e usarem os benefícios aprovados em Lei.

Diante disto, elencou-se atitudes simples que poderiam aumentar a eficácia dos certames e resultados das licitações, tais como se seguem: a) fornecer capacitação, nos moldes dos programas PRONATEC, Mulheres Mil, entre outros, para que os empresários estejam conscientes e preparados sobre a relevância dos processos públicos de licitação e seu impacto no desenvolvimento local; b) o SEBRAE e outras entidades do Sistema "S", como o Clube dos Diretores Lojistas - CDL, inseridos na região, poderiam ofertar cursos de capacitação gratuitos ou de baixo custo como o de "custos e formação de preço" para que os empreendedores tenham noção de um preço justo e até onde podem baixar seus lances nas compras governamentais, para que não tenham prejuízos e cumpram suas obrigações legais, evitando multas e sanções do governo; c) contadores e técnicos em contabilidade precisam se capacitar para auxiliar as empresas no mercado de compras públicas; d) o governo deveria capacitar os servidores para serem mais solícitos quanto ao esclarecimento de dúvidas dos participantes das licitações; e) as divulgações das licitações federais deveriam ser mais amplas, incluindo, sobretudo, as impressas regionais.

$\mathrm{O}$ resultado da pesquisa apontou, ainda, que as empresas afirmam estar preparadas para as licitações que tenham produtos com critérios de sustentabilidade. No entanto, este trabalho se propôs o estudo de produtos sustentáveis e não empresas sustentáveis. As exigências para aquisição de um bem sustentável vão de um simples selo de eficiência e/ou qualidade, que atendam às especificações técnicas e requisitos estabelecidos por instituições credenciadas, como INMETRO, ANVISA e PROCEL, até às certificações mais complexas como as normas da ABNT (ISO) e outros.

Observados estes princípios, espera-se ocorrer o crescimento econômico das MPEs na região, com melhor distribuição da renda e aumento dos postos de trabalho. Deste modo, a economia local também cresce, e há retorno para a sociedade, a qual pode receber bens e serviços preocupados com a sustentabilidade. Por fim, aumenta-se a qualidade de vida da população, enquanto o Estado Brasileiro promove o desenvolvimento nacional de forma sustentável.

Como propostas de estudos futuros, este trabalho poderá ser desenvolvido junto às empresas de serviços ou a outras atividades não 
contempladas nesta pesquisa. Sugere-se, também, uma futura pesquisa de verificação da variação financeira do gasto público entre as compras sustentáveis e convencionais, relacionando os resultados de eficiência e benefícios dos produtos e serviços sustentáveis ao longo de sua vida útil.

\section{Referências}

ALMEIDA, Henrique. PNUMA dará apoio a governos para direcionarem gastos públicos para produtos ecológicos. Publicado em 11 abril de 2014. Disponível em:

<http://www.pensamentoverde.com.br/sustenta bilidade/pnuma-dara-apoio-governos-paradirecionarem-gastos-publicos-para-produtosecologicos/> Acesso em: 03 jun. 2014.

BABBIE, Earl. Métodos de Pesquisas de Survey. Tradução Guilherme Cezarino. Belo Horizonte: Ed. UFMG, 1999, 519 p.

BARRETO, Luiz. O município contratando com a MPE. In: FERNANDES, Jorge Ulisses Jacoby. $O$ governo contratando com as micro e pequenas empresas: $o$ estatuto da micro e pequena empresa fomentando a economia do país. Brasília: SEBRAE, 2013.

BIDERMAN, Rachel; MACEDO, Laura Silva Valente de; MONZONI, Mario, MAZON, Rubens. Guia de compras públicas sustentáveis: uso do poder de compra do governo para a promoção do desenvolvimento sustentável. 2 ed. Editora FGV, Rio de Janeiro, 2008.

BRASIL. Conselho Superior da Justiça do Trabalho. Guia de Contratações Sustentáveis da Justiça do Trabalho/Brasil. Conselho Superior da Justiça do Trabalho. 2. ed., revisada, atualizada e ampliada - Brasília, 2014c. Disponível em: http://www.csjt.jus.br/c/document_library/get_f ile?uuid=750deba9-30cc-4ead-a04c$6 \mathrm{fcf} 316 \mathrm{c} 9 \mathrm{e} 8 \mathrm{e} \&$ groupId=955023 $>$ acesso em: 05 jun. 2014.

\section{Constituição Da República} Federativa Do Brasil De 1988. Disponível em: $<$

http://www.planalto.gov.br/ccivil_03/constituic ao/constituicao.htm> Acesso em: 20 maio 2014.

.Código Civil, Lei no 10.406 , de 10 de janeiro de 2002. Disponível em: < http://www.planalto.gov.br/ccivil_03/leis/2002/ 110406.htm

>. Acesso em: 12 jun. 2014.

Lei Complementar $\mathrm{N}^{0} \mathbf{1 2 3}$, de 14 de Dezembro de 2006. Disponível em: < http://www.planalto.gov.br/ccivil_03/leis/lcp/lc p123.htm>. Acesso em: 12 jun. 2014.

\section{Lei $N^{\circ}$ 8.666, De 21 de Junho de}

1993. Disponível em: <

http://www.planalto.gov.br/ccivil_03/leis/18666 cons.htm. Acesso em: 20 maio 2014.

\section{Ministério do Meio Ambiente. Plano}

de ação para produção e consumo sustentáveis - PPCS. Sumário Executivo. Brasília: 2011c. Disponível em: <http://www.mma.gov.br/images/arquivos/resp onsabilidade_socioambiental/producao_consum o/PPCS/PPCS_Sumario\%20Executivo.pdf $>$. Acesso em: 29 maio 2014.

Ministério do Planejamento, Orçamento e Gestão (MPOG). Comprando das micro e pequenas empresas. Caderno de Logística $n^{\circ}$ 4. 2013a. Disponível em: <http://www.comprasgovernamentais.gov.br/ar quivos/sustentabilidade/comprando-das-microe-pequenas-empresas-revisado.pdf $>$. Acesso em: 05 jun. 2014. Ministério do Planejamento, Orçamento e Gestão. Secretaria de Logística e Tecnologia da Informação. Informações gerenciais de contratações públicas sustentáveis janeiro a março de 2014. 2014b .Disponível em: $<\mathrm{http}: / /$ www.comprasgovernamentais.gov.br/go verno/informacoes-gerenciais/relatorios $>$. Acesso em: 10 jun. 2014.

Ministério do Planejamento, Orçamento e Gestão. Secretaria de Logística e Tecnologia da Informação. Informações gerenciais de contratações e compras públicas janeiro a março de 2014. 2014c. 
Disponível em:

<http://www.comprasgovernamentais.gov.br/go verno/informacoes-gerenciais/relatorios $>$.

Acesso em: 10 jun. 2014.

Ministério do Planejamento, Orçamento e Gestão. Secretaria de Logística e Tecnologia da Informação. Informações gerenciais de contratações públicas sustentáveis janeiro a dezembro de 2013. 2014d. Disponível em:

<http://www.comprasgovernamentais.gov.br/go verno/informacoes-gerenciais/relatorios $>$. Acesso em: 10 jun. 2014.

BRUNDTLAND, Gro Harlem. Our Common Future. Oxford: Oxford University Press, 1987.

BURG, Fernando; BURG, Giovane Matias; ÁVILA, Lucas Veiga; HOFFMAN Celina;

MADRUGADA, LúcIa Rejane Rosa Gama. A Perspectiva Da Sustentabilidade No Setor Do Transporte Rodoviário. Revista Educação Ambiental em Ação, n. 46. 2014.

CASTRO, Antonio de Oliveira. Como participar de licitação pública. 2010, Recife: SEBRAE. 56p. Disponível em: <http://www.fomentanacionalsebrae.com.br/do wnloads>. Acesso em: 10 maio de 2014.

CERINO, Pedro de Jesus. Micro e pequenas empresas e as compras governamentais: uma abordagem sobre a aplicação do capítulo $\mathrm{V}$ da Lei 123/06, no Brasil e em Roraima.

Dissertação. Porto Alegre, 2009.

CLARO, Priscila Borin de Oliveira; CLARO, Danny Pimentel; AMÂNCIO, Robson. Entendendo o conceito de sustentabilidade nas organizações. Revista de Administração da Universidade de São Paulo, v. 43, n. 4, 2008.

FARIA JUNIOR, Cyonil; BERNADES, Sandro Henrique. Licitações e Contratos. $2^{\circ}$ ed. Elsevier. Rio de Janeiro: 2010. 376 p.

FERNANDES, Jorge Ulisses Jacoby. O governo contratando com as micro e pequena empresa fomentando a economia do país. Brasília: SEBRAE. 106 p. 2013.
FREITAS, Claudio Luiz de; BORGERT, Altair; PFITSCHER, Elisete Dahmer. Agenda Ambiental Na Adiministração Pública: Uma Análise Da Aderência De Uma Ifes As Diretrizes Propostas Pela A3p. XI Colóquio Internacional Sobre GestãoUniversitária na América do Sul. II Congresso Internacional IGLU. Florianópolis. 2011. Disponível em: <http://repositorio.ufsc.br/xmlui/bitstream/hand le/123456789/30051/7.7.pdf?sequence=1\&isAl lowed=y>. Acesso em: 12 de jul. 2014.

FREITAS, Henrique et al. O método de pesquisa survey. Revista de Administração, São Paulo, v. 35, n. 3, p.105-112, jul. 2000. Trimestral. Disponível em:

$<$ http://www.unisc.br/portal/upload/com_arquiv o/o_metodo_de_pesquisa_survey.pdf $>$. Ácesso em: 20 out. $201 \overline{3}$.

FREITAS, Thiago. Aquisições públicas sustentáveis: o princípio da sustentabilidade encarado para além da questão ambiental. Revista Brasileira de Políticas Públicas (Brazilian Journal of Public Policy), v. 2, n. 1, 2012.

IBGE. Instituto Brasileiro de Geografia e Estatística. Cidades@. Disponível em: <http://www.ibge.com.br/cidadesat/xtras/perfil. php?lang=\&codmun=320490\&search=espiritosanto|sao-mateus>. Acesso em: 10 de jul. de 2014.

ICLEI, Governos Locais pela Sustentabilidade. Compras sustentáveis pela inovação e por uma economia verde inclusiva. Projeto Compras e Inovação. Relatório de Diretrizes aos Planos de Gestão de Logística Sustentável. 2013. Disponível em:

<http://archive.iclei.org/index.php?id=7172>. Acesso em: 05 maio 2014.

INCAPER. Instituto Capixaba de Pesquisa, Assistência Técnica e Extensão Rural. Programa de Assistencia Técnica e Extensão Rural PROATER 2011 - 2013. São Mateus Planejamento e Programação de ações 2011. Disponível em:

<http://www.incaper.es.gov.br/proater/municipi os/Nordeste/Sao_Mateus.pdf> Acesso em: 10 de jul. de 2014. 
INSTITUTO DE PESQUISA ECONÔMICA APLICADA - IPEA, O uso do poder de compra para a melhoria do meio ambiente. Série Eixos do Desenvolvimento Brasileiro n. 82. Brasília:

IPEA, 2011. Disponível em:

<http://ipea.gov.br/portal/images/stories/PDFs/ comunicado/110301_comunicadoipea82.pdf $>$. Acesso em 10 de jul 2014.

IFES, Instituto Federal do Espírito Santo.

Relatório de Gestão 2012. 2013. Disponível em:

<ftp://ftp.sm.ifes.edu.br/relatorio_gestao/relator io_de_gestao-campus_sao_mateus-2012.pdf $>$. Acesso em: 10 de jul. 2014 .

JUSTEN FILHO, Marçal. Comentários a lei das licitações e contratos administrativos. 14. ed. São Paulo: Dialética, 2010.

MACHADO, Jacimara Guerra. Gestão ambiental na administração pública: a mudança dos padrões de consumo "começa em casa". Dissertação (Mestrado em

Desenvolvimento Sustentável). Centro de Desenvolvimento Sustentável. Universidade de Brasília, Brasília, 2002.

MELLO, Celso Antonio Bandeira de. Curso de direito administrativo. 29. ed., rev. e atual. até a Emenda Constitucional 68, 21.12.2011. São Paulo.SP: Malheiros, 2012. p. 532.

MUKAI, Toshio. Estatutos jurídicos de licitações e contratos administrativos. São Paulo: Saraiva, 1990.

SAMPAIO, Adilson da Hora; CABRAL, Sandro. Um estudo sobre a participação das micro e pequenas empresas nos pregões eletrônicos realizados na FIOCRUZ/BA. Dissertação. 2012. Disponível em :< http://www.adm.ufba.br/sites/default/files/publi cacao/arquivo/adilson_da_hora_sampaio.pdf $>$ Acessado em: 01 de jul. 2014.

SAMPIERI, Roberto Hernández; COLLADO, Carlos Fernández; LUCIO, Pilar Baptista.
Metodologia da Pesquisa. Trad: Fátima Conceição Murad, Melissa Kassner, Sheila Clara Dystyler Ladeira. 2006.

\section{SEBRAE - SERVIÇO BRASILEIRO DE APOIO ÀS MICRO E PEQUENAS EMPRESAS. Lei geral da micro e pequena empresa. Conheça as mudanças, os procedimentos e os benefícios, 2007, Disponível em: \\ <http://www.abts.org.br/arquivos/Lei_Geral_da s_MPEs.pdf > Acesso em: 05 jun. $201 \overline{4}$.}

SAEB - SECRETARIA DA ADMINISTRAÇÃO DO ESTADO DA BAHIA; ICLEI - INTERNATIONAL COUNCIL FOR LOCAL ENVIRONMENTAL INITIATIVEs - Brasil. Compras públicas sustentáveis: uma abordagem prática. Organizadores: Florence Karine Laloë, Paula Gabriela de Oliveira Freitas. 1. ed. Salvador: s. ed, 2012.

UNITED NATIONS. Public procuremente as a tool for promoting more Sustainable consumption and Production patterns. Sustainable Development Innovation Briefs. Issue 5. New york, 2008. Disponível em: $>$ http://esa.un.org/marrakechprocess/pdf/innova tionbriefs_no5.pdf>. Acesso em: 05 jun. 2014.

VERGARA, Sylvia Constant. Projetos e relatórios de pesquisa em administração. $13^{\circ}$ ed. São Paulo: Atlas, 2011.

VIEIRA, José Eugênio. Os pequenos negócios e o desenvolvimento capixaba. In: Revista Anuario IEL 200. Maiores empresas do Espírito Santo. Edição 2013. Economia, p. 4446.

ZAMBON, Bruno Pagotto; RICCO, Adriana Sartório. Sustentabilidade empresarial: uma oportunidade para novos negócios. 2011.

Disponível em: <

http://www.craes.org.br/arquivo/artigoTecnico/ Artigos_Sustentabilidade_Empresaria_Uma_op ortunidade_para_novos_negciosl.pdf $>$. Acesso em: 01 de jul. de 2014. 